\title{
Preliminary Results from a Magnetotelluric Transect Across the Northern Paraguay Belt
}

Alane Neves Barbosa, IAG/USP and Mauricio de Souza Bologna, IAG/USP

Copyright 2019, SBGf - Sociedade Brasileira de Geofísica

This paper was prepared for presentation during the $16^{\text {th }}$ International Congress of the Brazilian Geophysical Society held in Rio de Janeiro, Brazil, 19-22 August 2019.

Contents of this paper were reviewed by the Technical Committee of the $16^{\text {th }}$ International Congress of the Brazilian Geophysical Society and do not necessarily represent any position of the SBGf, its officers or members. Electronic reproduction or storage of any part of this paper for commercial purposes without the written consent of the Brazilian Geophysical Society is prohibited.

\section{Abstract}

The study area has controversial tectonic models for the Gondwana formation, encompassing ensialic model and the closure of a wide ocean between the Amazon Plate and the western block of Paraná. In this work, we present the first results from a magnetotelluric study across the Paraguay-Araguaia Belt Conductivity Anomaly (PACA) to obtain a geoelectric model of the lithosphere. The data set consists of a north-south profile composed of 11 broadband MT stations evenly spaced by approximately $12 \mathrm{~km}$. Visual inspection of the phase pseudosections show two main conductive zones. The first zone corresponds to the Paraná Basin, being almost 1D. The second zone is more complex, and probably associated with the PACA. The behavior of the induction arrows is indicative of an almost 2-D environment for the PACA, but the phase tensor analysis suggests a 3D structure. This case illustrate the importance of performing quantitative dimensionality analysis of the MT impedance tensor before data inversion

\section{Introduction}

The Paraguay-Araguaia Belt Conductivity Anomaly (PACA, BOLOGNA et al, 2014) is an extensive conductivity anomaly, approximately $1200 \mathrm{~km}$ in length, in the subsurface, surrounding the south and southeast border of the Amazon Craton. Its southern segment is in the Northern Paraguay Belt, a region that has been the subject of recurrent discussions about its evolutionary model and the formation of the supercontinent Gondwana.

Trompette (1994), advocates an ensialic evolution for the Paraguay Belt. In contrast, paleogeographic studies of Gondwana (TRINDADE et al., 2006; TOHVER et al., 2012) suggest that these cratons were already separated by ta large ocean basin at the southern margin of the Amazon Craton.

Different geophysical studies on the continental lithosphere of the South American plate, using techniques such as gravity, receptor function, and tomography (ASSUMPÇÃO et al, 2013; VAN DER MEIJDE et al, 2013) have been made in recent years to determine the lithospheric structure of the South American plate.
However, the relatively low resolution of these data has prevented the location of the plate boundaries, hampering the reconstruction of the West Gondwana.

In this work, we propose a magnetotelluric (MT) study of the region between the Amazonian Craton and the Paraná Basin, crossing orthogonally the PACA.

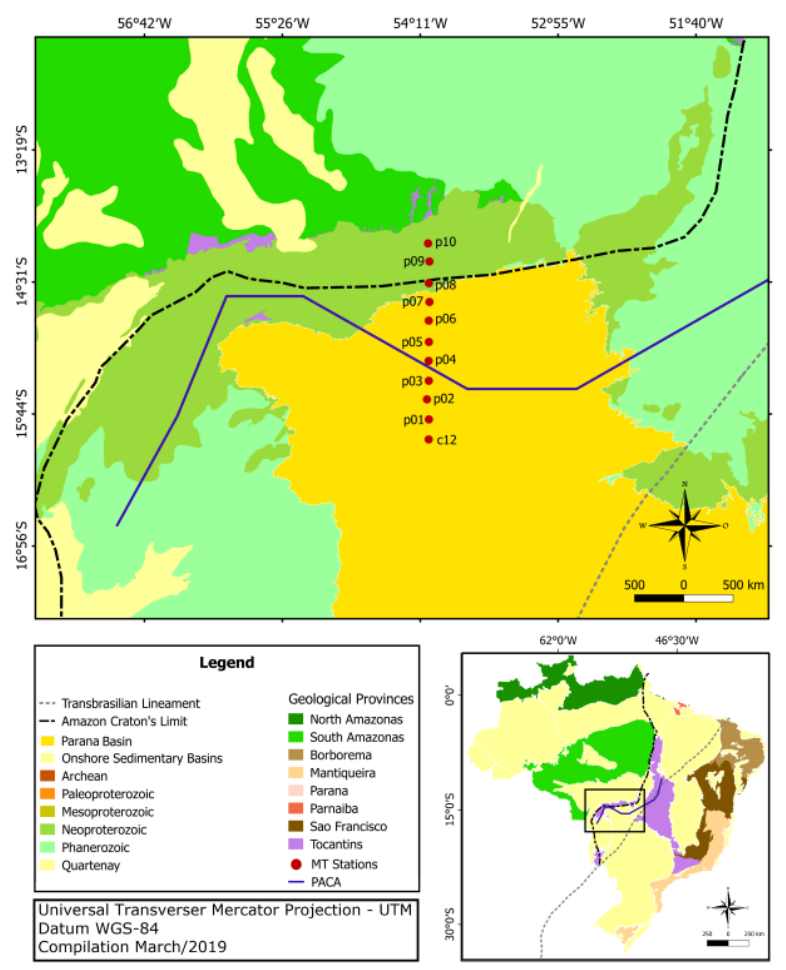

Figure 1 - Location of the MT sites on a generalized geological map, extracted from Bizzi et al. (2003) and Cordani et al. (2016), with the PACA contour defined by Bologna et al (2014).

The proposed method (MT) provides images of the subsurface with an intermediate resolution between that obtained by the reflection seismic and the one obtained by the potential methods (MENEZES, 2013). This method is sensitive to a physical parameter (electrical conductivity) that in the terrestrial interior varies in several orders of magnitude, which gives it great sensitivity to anomalies. In addition, resistivity depends on minor components of rocks, such as fluid content, carbon, sulfides, etc. Therefore, MT measurements are complementary to other geophysical techniques, such as seismic and potential methods, which are sensitive to the total rock properties. 


\section{Method}

MT, proposed by Tikhonov (1959) and Cagniard (1953), is based on measuring both the electric and magnetic fields at the surface. These signals are generated by different sources: low frequency, through the interaction of the solar wind with the magnetosphere, and; high frequency, through meteorological phenomena in the atmosphere. This method is based on the concept that the propagation of electromagnetic waves induces telluric currents. The result of the field data acquisition are time series that can be converted to the frequency domain. These measurements correlate with lithological, mineralogical, temperature, permeability and other variations. Further information on the MT method is described in detail in Simpson and Bahr (2005).

The Geomagnetism studies group of the National Institute of Space Research carried out the MT campaign. The data was collected using the broadband MT equipment (Metronix GMS06). The average recording time was typically of around $24 \mathrm{hr}$.

The first step of the data processing was to estimate the tensor impedance for each MT site. For this, the robust code of Egbert (1997) was applied. This code is based on the weighted minimization of the difference between the measured and predicted values for the electric and magnetic fields, so that the disturbed values are not dominant in the final estimate. The robust statistic is applied in order to remove the outliers from the obtained curves. The tensor impedance estimation is presented through its components, apparent resistivity and phase.

The phase tensor (CALDWELL et al., 2004) is defined as an amount derived from the tensor impedance representing the regional phase relationship between the electric and magnetic fields. In general, the phase tensor can be represented graphically by an ellipse, the axes being regulated from the main values of the tensor, $\Phi$ $\max$ and $\Phi \mathrm{min}$; the angle that the reference axis of the ellipse makes with the major axis is $\beta$ and the angle that the reference axis makes with the coordinate system is $\alpha$. In this work, we decompose the phase tensor in min axis and normalized skew, to better visualize the dimensionality and directionality of the structures, thus avoiding misinterpretations as suggested by Booker (2013).

To analyze the dimensionality of the medium is taken into account the aspects of the ellipse generated by calculating the phase tensor. In a 1D medium, the graphical representation of the ellipses will be closer to the circles given to a simpler geological structure. For a $2 \mathrm{D}$ medium, there is an ellipse with the major axis aligned with the reference axis $(\beta=0)$, this axis must be perpendicular to the direction of the layer if the ellipse is on a conductive or parallel medium if the ellipse is in a resistive medium. If the major axis is misaligned with the reference axis it is invoked in a regional structure with three-dimensional heterogeneities $(\beta \neq 0)$. These structures, when resistive, will rotate the major axis so that the ellipse is parallel to them. If these structures are conductive, the major axis will rotate so that the ellipse is positioned perpendicular to them.

\section{Preliminary Results}

Figure 2 shows the pseudosections for the impedance phases of both measurement directions. Although the analysis of pseudosections is considered only a qualitative analysis, this step gives an initial impression of the distribution of electrical conductivity in subsurface. In general, the pseudosections of the phase are more uniform than apparent resistivity because phases are not affected by static shift affects. In the phase pseudosections, regions with phases smaller than $45^{\circ}$ are more resistive regions, whereas regions larger than $45^{\circ}$ more conductive. Thus, from the phase pseudosections shown in Figure 2 we observe two conductive zones. The first zone is located between the stations c12 - p07 and between the periods $00001-0.1$ second (s). This conductive region is related to the Paraná sedimentary basin. The second zone is located between the stations p03 - p09 and between the periods $0.1-100 \mathrm{~s}$, and probably is associated with the PACA.

Figure 3 shows the induction arrows. These are arrows representations of the relationship between the vertical and the horizontal component of the magnetic field. Induction arrows can be used to infer the presence or absence of lateral effects on conductivity because of the lateral conductivity gradients generated by vertical magnetic fields. Thus, at the Parkinson's convention, the graphs point to internal anomalous current concentrations (PARKINSON, 1959). The design of induction arrows for the period 102.4 seconds, it is observed that it seems an almost 2D environment, since the arrows point almost parallel to the profile reversing around station p06, similar to a structure reported by Bologna et al. (2014). Apparently, the vectors correspond to a linear body of east - west direction. 

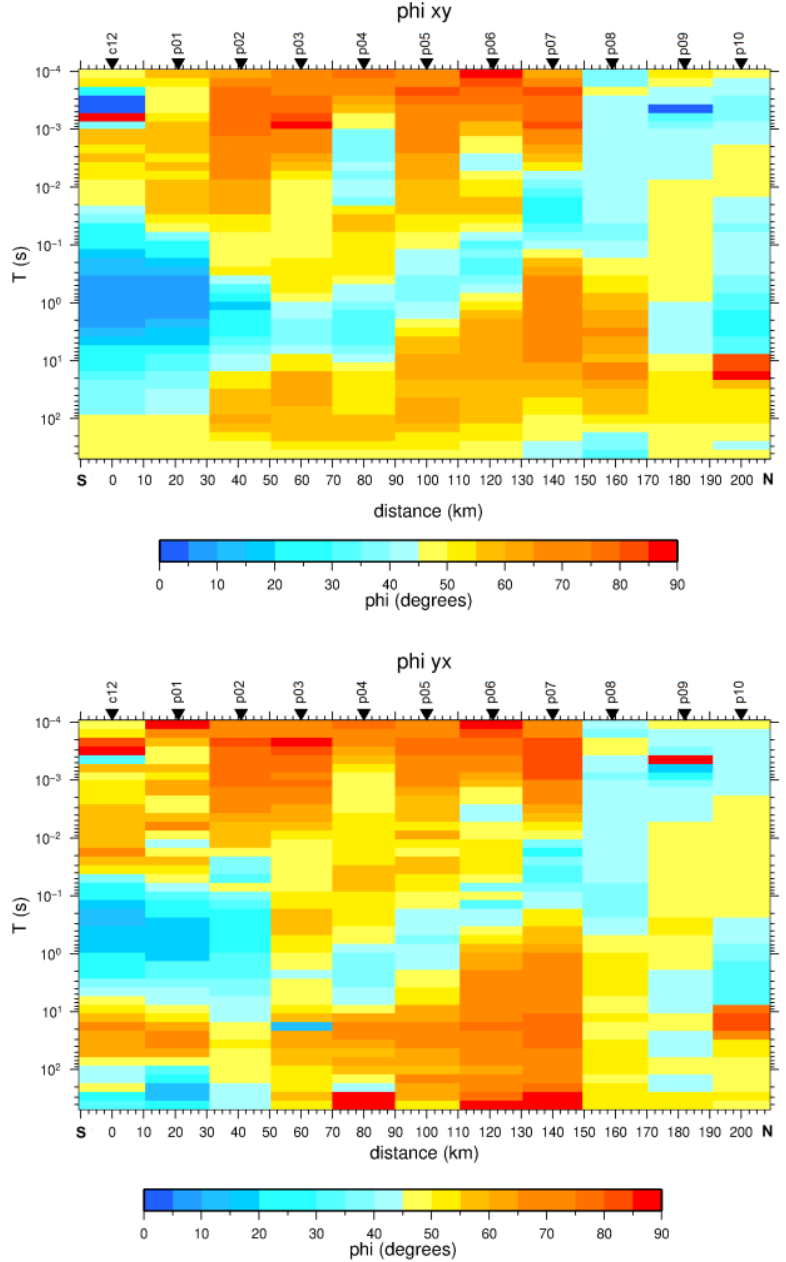

Figure 2 - Pseudosections of $X Y$ and $Y X$ modes phases from all sites.

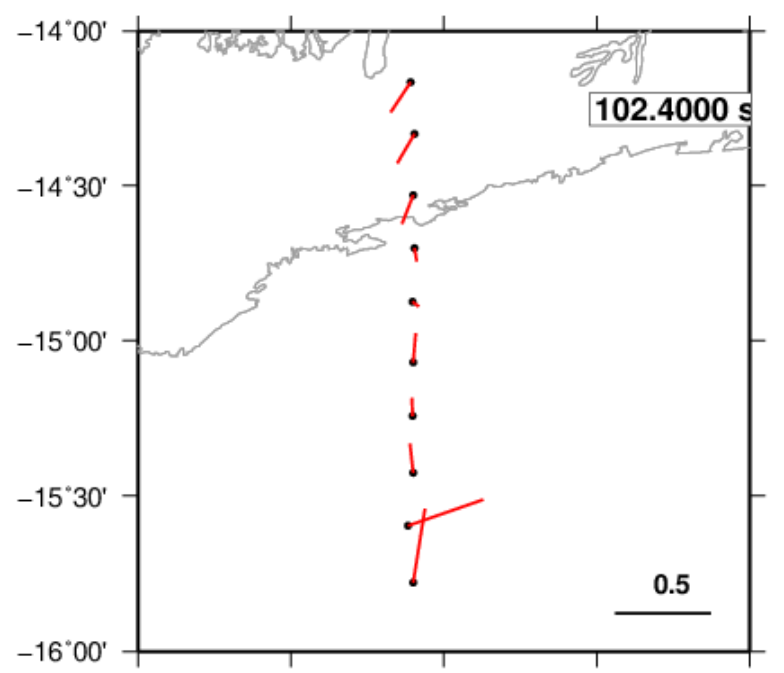

Figure 3 - Induction arrows for the period $102.4000 \mathrm{~s}$

A map of tensor phase ellipses at all frequencies is shown in Figure 4. At short periods, ellipses are almost circular, indicating a one-dimensional environment. In intermediate periods (approximately 0.01 and $1 \mathrm{~s}$ ), ellipses are less rounded with intermediate values for the $\Phi$ min and $\beta$ near zero, which suggests a 3-D environment. Higher $\beta-$ values are observed longer periods, particularly in the region associated with the PACA.

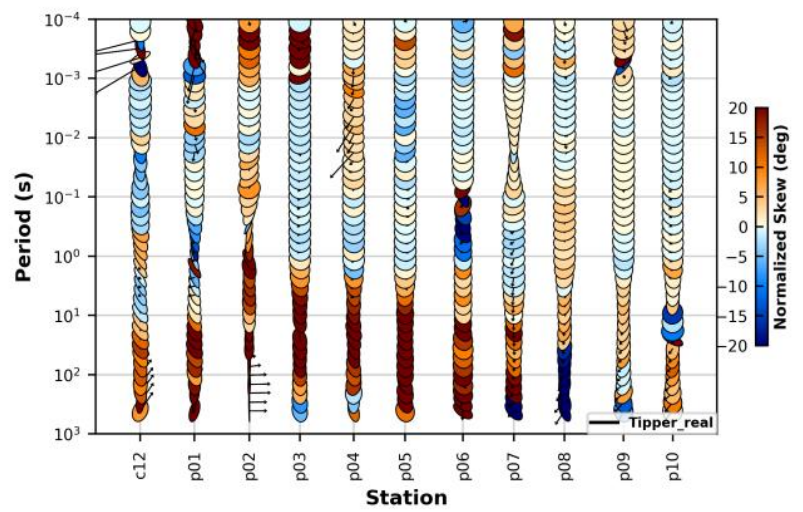

Figure 4 - Pseudosection of the phase tensors for the broadband MT data in function of skew or $\beta$.

\section{Conclusions}

At short periods ( $<10 \mathrm{~s}$ ) our MT data are closely 1D or 2D. These periods are representative of relatively shallow structures, including the Paraná Basin and cratonic cover at longer periods, for which the MT responses are dominated by the PACA, the data can be 3D, despite visual inspection of the induction arrows have suggested a 2D environment. Hence, to obtain a reliable resistivity model we should perform either 2D inversions of a subset of data or 3D inversion of the full dataset.

\section{Acknowledgments}

The authors are grateful to the dedicated field and processing team of the Geomagnetism group at INPE for the data collection. One of the authors (Alane Neves Barbosa) have master's degree fellowship from CNPq (169807 / 2018-5).

\section{References}

ASSUMPÇÃO, $M$ et al. Models of crustal thickness for South America from seismic refraction, receiver functions and surface wave tomography. Tectonophysics, [s.l.], v. 609, p.82-96, dez. 2013. Elsevier BV. http://dx.doi.org/10.1016/j.tecto.2012.11.014.

BIZZI, Luiz Augusto et al (Ed.). Geologia, Tectônica e Recursos Minerais do Brasil: Texto, Mapas \& SIG. Brasilia: CPRM - Serviço Geológico do Brasil, 2003. 692 p.

BOLOGNA, M. S. et al. Paraguay-Araguaia Belt Conductivity Anomaly: A fundamental tectonic boundary in South American Platform imaged by electromagnetic induction surveys. Geochemistry, Geophysics, Geosystems, [s.I.], v. 15, n. 3, p.509-515, mar. 2014. 
American Geophysical Union (AGU). http://dx.doi.org/10.1002/2013gc004970.

BOOKER, John R.. The Magnetotelluric Phase Tensor: A Critical Review. Surveys In Geophysics, [s.I.], v. 35, n. 1, p.7-40, 23 maio 2013. Springer Nature. http://dx.doi.org/10.1007/s10712-013-9234-2.

CALDWELL, T. G.; BIBBT, H. M.; BROWN, C; The magnetotelluric phase tensor. Geophys. J. Int., 158, 457469. 2004. Doi: 10.111/j.1365-246X.2004.02281.x.

CORDANI, U. G.; RAMOS, V. A.; FRAGA, L. M.; CEGARRA, M.; DELGADO, I.; DE SOUZA, K. G.; GOMES, F. E. M.; SCHOBBENHAUS, C.; Tectonic Map of South America at 1:5.9 M, CGMW-CPRM-SEGEMAR. 2016. Printed by Gilbert Clarey Imprimeurs, Chambraylès-Tours, France.

EGBERT, G. D.; KELBERT, A.; Computational recipes for electromagnetic inverse problems. Geophys. J. Int., 189, 251-267. 2012. Doi: 10.1111/j.1365-246X.2011.05347.x

MENEZES, P. T. L.; Fundamentos do Método Magnetotelúrico na exploração de Hidrocarbonetos. Rio de Janeiro. SBGF. 2013.

PARKINSON, W. D.. Directions of Rapid Geomagnetic Fluctuations. Geophysical Journal International, [s.I.], v. 2, n. 1, p.1-14, mar. 1959. Oxford University Press (OUP). http://dx.doi.org/10.1111/j.1365-246x.1959.tb05776.x.

SIMPSON, F.; BAHR, K.; Practical Magnetotellurics. Cambridge: Cambridge University Press, 2005. 270 p.

SIRIPUNVARAPORN, W.; EGBERT, G.; An efficient data-subspace inversion method for 2D magnetotelluric data, Geophysics, 2000, vol. 65, pp 791-803

TIETZE, K; RITTER, O. Three-dimensional magnetotelluric inversion in practice-the electrical conductivity structure of the San Andreas Fault in Central California. Geophysical Journal International, [s.I.], v. 195, n. 1, p.130-147, 4 jul. 2013. Oxford University Press (OUP). http://dx.doi.org/10.1093/gji/ggt234.

TOHVER, E. et al. Closure of the Clymene Ocean and formation of West Gondwana in the Cambrian: Evidence from the Sierras Australes of the southernmost Rio de la Plata craton, Argentina. Gondwana Research, [s.I.], v. 21, n. 2-3, p.394-405, mar. 2012. Elsevier BV. http://dx.doi.org/10.1016/j.gr.2011.04.001.

TRINDADE, R.I.F., D'AGRELLA-FILHO, M.S., EPOF, I., E BRITO NEVES, B.B., Paleomagnetism of Early Cambrian Itabaiana mafic dikes (NE Brazil) and the final assembly of Gondwana: Earth and Planetary Science Letters, 2006, v. 244, p. 361-377, doi: 10.1016 /j .epsl .2005 .12 .039 .

TROMPETTE, R. (1994) Geology of Western Gondwana (2000-500): Pan-African-Brasiliano Aggregation of South America and Africa. Balkema, Rotterdam, $350 \mathrm{p}$.

VAN DER MEIJDE, M.; JULIÀ, J.; ASSUMPÇÃO, M. Gravity derived Moho for South America. Tectonophysics, [s.l.], v. 609, p.456-467, dez. 2013. Elsevier BV. http://dx.doi.org/10.1016/j.tecto.2013.03.023. 